\title{
Prevalence and factors associated with supportive care needs among newly diagnosed Mexican breast cancer patients
}

\author{
Adriana Pérez-Fortis ${ }^{1}$ (D) Joke Fleer ${ }^{1} \cdot$ Juan José Sánchez-Sosa $^{2}$. \\ María Guadalupe Veloz-Martínez ${ }^{3}$ • Patricia Alanís-López ${ }^{3}$ • Maya J. Schroevers ${ }^{1}$. \\ Adelita V. Ranchor ${ }^{1}$
}

Received: 14 September 2016 / Accepted: 4 May 2017/Published online: 17 May 2017

(C) The Author(s) 2017. This article is an open access publication

\begin{abstract}
Purpose Mexican breast cancer patients are generally diagnosed in advanced stages of the disease and often experience delays in cancer treatment delivery. Currently, little is known about these patients' psychological care needs. This study assessed levels and correlates of supportive care needs of Mexican breast cancer patients around the time of cancer diagnosis.

Methods One hundred seventy-three newly diagnosed Mexican breast cancer patients participated in the study. Supportive care needs, anxiety, depression, and patients' sociodemographic and clinical characteristics were assessed. Multiple regression analyses were used to examine factors associated with care needs. Results Up to $44 \%$ of patients showed unmet care needs. Health system/information needs were the most prevalent (68\%), while physical/daily living needs the least (19\%). Level of depressive symptoms was most consistently related to care needs. Patients with higher levels of depressive symptoms had higher psychological $(\beta=0.38)$, physical/daily living $(\beta=0.43)$, patient care/support $(\beta=0.17)$, and additional
\end{abstract}

Electronic supplementary material The online version of this article (doi:10.1007/s00520-017-3741-5) contains supplementary material, which is available to authorized users.

Adriana Pérez-Fortis

a.perez.fortis@umcg.nl

1 Department of Health Sciences, Health Psychology Section, University of Groningen, University Medical Center Groningen, Groningen, The Netherlands

2 Faculty of Psychology, National University of Mexico (UNAM), Mexico City, Mexico

3 Hospital of Gynecology and Obstetrics, National Medical Center "La Raza," Mexican Institute of Social Security (IMSS),

Mexico City, Mexico unmet care needs $(\beta=0.30)$, than patients with lower levels of depressive symptoms.

Conclusions This study suggests that mainly health system/ information needs arise at the time of cancer diagnosis among Mexican breast cancer patients. Patients suffering high levels of depressive symptoms reported the highest levels of unmet needs. Future studies should be conducted to elucidate the care needs throughout the disease trajectory, as such information can inform health care professionals and policy makers and lead to improvements in the organization and provision of health care services for Mexican breast cancer patients.

Keywords Breast cancer · Oncology · Care needs · Psychosocial $\cdot$ Latinas

\section{Introduction}

Comprehensive breast cancer care in Latin America, including Mexico, is poor compared to North America or Europe [1, 2]. Patients are generally diagnosed at a young age in advanced stages of the disease and experience a relatively long delay in care delivery [1-3]. It has been shown that more than $80 \%$ of Mexican breast cancer patients present clinical levels of anxiety and around $44 \%$ exhibit clinical levels of depression at the time of diagnosis [4]. Moreover, breast cancer is the first cause of death among women aged 35-64 years old in Mexico [5]. Providing comprehensive cancer care within the Mexican health care system is a challenge, partly due to the lack of a national cancer plan [6]. Identifying the patients' supportive care needs is needed to prioritize and guide the provision of care $[7,8]$. Supportive care needs refer to the patients' perceptions of their need for help in specific domains (see Supporting Table 1 online), and the extent to which these needs are met or 
unmet [9]. This study aims to investigate such supportive care needs in Mexican breast cancer patients.

Although there are currently no published studies illustrating the specific supportive care needs of Mexican women with breast cancer, a recent study with Mexican heterogeneous cancer patients who previously underwent surgery showed that the top three unmet care needs of these patients were related to health system/information, physical/daily living, and psychological domains [10]. Recently, a systematic review of 23 studies on the supportive care needs among breast cancer patients, the majority of whom were studied while receiving cancer treatment, found that women's needs clustered around the psychological and health system/information needs [11].

Besides investigating and identifying the specific supportive care needs of Mexican breast cancer patients, it is also important to identify the main characteristics of patients in need of care. According to the systematic review, predictors of higher levels of needs included a younger age, advanced disease stage, shorter time since diagnosis, and higher levels of anxiety, depression, and distress [11]. Some studies suggest that higher levels of education were also associated with greater care needs $[12,13]$, while others found that lower levels of education were associated with greater needs $[14,15]$ which seems to suggest that different types of needs may characterize such populations. Uncovering the characteristics of Mexican breast cancer patients that are linked to their levels of supportive care needs would identify vulnerable patient subgroups with higher needs for care. The primary aim of this study was to evaluate the levels of supportive care needs in newly diagnosed Mexican breast cancer patients. A second objective was to identify sociodemographic and clinical characteristics and psychological symptoms associated with patients' supportive care needs.

\section{Method}

For this study, we used the baseline data collected for an ongoing longitudinal study on supportive care needs among Mexican breast cancer patients.

\section{Participants and setting}

A consecutive sample of breast cancer patients was recruited at the Gynecology and Obstetrics Hospital from the "La Raza" National Medical Center in Mexico City. Patients' inclusion lasted from May 2014 until July 2015. Inclusion criteria were (1) age between 18 and 75 years old, (2) primary breast cancer diagnosis, confirmed by a biopsy test, and (3) comprehension of the Spanish language. Exclusion criteria were (1) a serious diagnosed psychiatric disorder that implied hospital admission, (2) medical treatment that had already begun, (3) involvement in another study at the time of inclusion, and (4) being male.
The study was approved by the hospital's research and ethics committees (R-2014-3504-40). Three graduated psychologists trained in medical and oncological terms and in the application of interviews to oncological patients participated in patient recruitment and data collection under the direct supervision of an oncologist from the hospital. Potential participants were identified by the graduates through the electronic medical records in the hospital and approached either by telephone or while at the outpatient clinic, chemotherapy, or surgery services of the hospital. Eligible patients were informed about the study and invited to participate. Patients who agreed to participate signed informed consent and were interviewed.

\section{Measures}

Data from self-report questionnaires were collected using a faceto-face semi-structured interview, because a substantial number of the patients treated in Mexican public hospitals have a low literacy level. Interviewers were specifically trained to avoid any action that might induce participants' responses.

Supportive care needs were measured with the short form of the Supportive Care Needs Survey (SCNS-SF34) [16]. The original version of the instrument consisted of 34 items and five dimensions. In the present study, we added five items from the long version of the SCNS [17], because the aspects covered by those items were considered pertinent for the Mexican context (Supporting Table 2, online). These items were grouped as an extra dimension labeled "additional needs." The SCNS-SF34 employs a 5-point Likert response format as follows: $1=$ not applicable, which refers to not having the problem stated in each item, $2=$ satisfied, $3=$ low need, $4=$ moderate need, and $5=$ high need . The instrument measures perceived needs of patients for help and urgency of the need over the month preceding the interview. For the present study, we shortened this period to 2 weeks preceding the interview, given the longitudinal design of the study and the time periods between assessments. Summated scores were calculated for each dimension using standardized scores ranging from 0 to 100 . Higher scores reflected higher supportive care needs. Cronbach's alpha ranged from 0.70 to 0.95 among the five dimensions of the instrument, and the "additional needs" dimension showed an alpha of 0.78. At the start of this study, there was no available Spanishvalidated version of the SCNS-SF34. Thus, the instrument was translated into Spanish following a forward translation method. Next, two psychologists fluent in both languages evaluated whether the appropriate psychological meaning was kept for every item in the Spanish version. Finally, an expert judgment by two (different from the initial) expert independent psychologists was conducted to evaluate the adapted version and make adjustments to the final version. The version used in the present study was compared to the 
validated Spanish version recently published [10], and although the wording of some items tended to differ slightly, the content and meaning were the same.

Anxiety symptoms were measured with the 6-item short version of the state scale from the Spielberg State and Trait Anxiety Inventory (STAI) $[18,19]$. Patients rated the degree to which they were currently experiencing each anxiety symptom on a 4-point Likert scale, ranging from 1 (not at all) to 4 (very much). A total score was computed by summing the six items, once negative items had been transformed as appropriate. Higher scores reflected higher levels of anxiety. Cronbach's alpha for the scale was 0.81 .

Depressive symptoms were measured with the Spanish version of the Patient Health Questionnaire (PHQ-9) [20]. The PHQ-9 consists of nine items to measure depression severity. Patients rated the degree to which they experienced each depressive symptom in the 2 weeks preceding the interview on a 4-point Likert scale ranging from 0 (not at all) to 3 (nearly every day). A total score was computed by summing the nine items. Higher scores reflected higher levels of depression. Cronbach's alpha for the overall scale was 0.81 .

Information on age, marital status, education level, residence, work status, number of children, time since diagnosis, comorbidities, and occurrence of a life event during the 3 months preceding the interview were also collected during the interview. Medical information on the cancer stage was obtained from the patients' medical files. We did ask patients during the interview about their cancer stage, but we found that up to $32 \%$ of patients did not know about cancer stages or reported a cancer stage that was different from that contained in their medical file. Therefore, we did not include stage data from this source in the analyses about correlates of care needs.

\section{Statistical analyses}

We computed descriptive data on the characteristics of the sample. Originally, marital status and education had six answer categories; however, for the purpose of statistical analyses, answer categories were regrouped into two categories for marital status and three categories for schooling (Table 1). The prevalence of supportive care needs was computed for each dimension and for the total scale, based on the percentage of responses to each answer category of the SCNS. The proportion of responses to answer categories "low need" to "high need" were summed up and grouped under the label of "unmet needs." Additionally, we computed the percentage of responses, and each confidence interval (likelihood ratio method), on the "moderate need" and "high need" categories, to identify the top ten most prevalent unmet supportive care needs at itemlevel. To identify the characteristics of patients significantly associated with supportive care needs, multiple regression analyses were computed. We computed six multiple regression models using the enter method (one model for each supportive care need dimension). Dummy variables were created for variables with more than two categories. The variance inflation factor (VIF) was used to assess the multicollinearity among patient characteristics in the regression models. For the six regression models, the VIF was $<2.0$. All cited $P$ values were two-sided with a significance level of 0.05 . Analyses were conducted with SPSS software.

\section{Results}

\section{Characteristics of participants}

A total of 257 breast cancer patients were eligible to participate in the study, of whom 62 could not be reached. Of the 195 who were contacted about the study, 20 patients declined to participate, one did not attend the interview, and one was excluded, because the time since diagnosis was longer than 1 year, resulting in a final sample of 173 patients $(67 \%$ response rate). Sociodemographic and medical details are presented in Table 1.

Table 1 Descriptive characteristics of the sample $(n=173)$

\begin{tabular}{|c|c|c|}
\hline Characteristic & Mean \pm SD & $n(\%)$ \\
\hline Age (years) & $52.8 \pm 10.53$ & \\
\hline Number of children & $3 \pm 2$ & \\
\hline \multicolumn{3}{|l|}{ Marital status } \\
\hline With partner & & $117(67.6)$ \\
\hline Without partner & & $56(32.4)$ \\
\hline \multicolumn{3}{|l|}{ Education } \\
\hline Low $^{\text {a }}$ & & $54(31.2)$ \\
\hline Middle & & $104(60.1)$ \\
\hline High & & $15(8.7)$ \\
\hline \multicolumn{3}{|l|}{ Work status } \\
\hline Employed & & $61(35.5)$ \\
\hline Housewife/retired ${ }^{\mathrm{b}}$ & & $111(64.5)$ \\
\hline Time since diagnosis (months) & $1.9 \pm 2.0$ & \\
\hline \multicolumn{3}{|l|}{ Breast cancer stage } \\
\hline I & & $18(10.4)$ \\
\hline II & & $64(37.0)$ \\
\hline III-IV & & $68(39.3)$ \\
\hline Unknown & & $23(13.3)$ \\
\hline \multicolumn{3}{|l|}{ Comorbidities } \\
\hline Yes & & $99(57.2)$ \\
\hline No & & $74(42.8)$ \\
\hline \multicolumn{3}{|c|}{ Life events during the past 3 months } \\
\hline Yes & & $40(23.1)$ \\
\hline No & & $133(76.9)$ \\
\hline Anxiety & $14.45 \pm 4.08$ & \\
\hline Depression & $6.64 \pm 5.68$ & \\
\hline \multicolumn{3}{|l|}{$S D$ standard deviation } \\
\hline \multicolumn{3}{|l|}{${ }^{\mathrm{a}}$ Five patients had no education } \\
\hline${ }^{\mathrm{b}}$ Two patients were retired. A & ndicated to be & ployed \\
\hline
\end{tabular}




\section{Prevalence of supportive care needs}

Figure 1 summarizes the prevalence of supportive care needs overall and for each domain (for correlations and descriptions of the supportive care needs domains, see Supporting Table 2 online). Up to $44 \%$ of the participants showed unmet care needs overall. The most prevalent unmet care needs were health system/information needs $(68 \%)$, whereas the least prevalent unmet care needs were physical/daily living needs (19\%). In Table 2, the most prevalent unmet care needs of the patients at an item level are reported.

\section{Factors associated with patients' supportive care needs}

Results from the multiple regression analyses showed that age, marital status, education, comorbidities, life events, anxiety, and depressive symptoms were associated with at least one of the needs domains (Table 3 ). Results from the univariate association between the characteristics of the patients and their supportive care needs can be viewed online (Supporting Table 3).

Older patients showed lower physical/daily living care needs $(\beta=0.20)$ as well as lower sexual care needs $(\beta=-0.29)$, compared to younger patients. Patients with a partner reported higher sexual unmet care needs $(\beta=0.15)$ than patients without a partner. Patients with a high education level $(\beta=0.17)$ indicated higher psychological unmet care needs than those with a low education level.
Patients with comorbidities presented higher physical/daily living unmet care needs $(\beta=0.15)$ than patients with no comorbidities. Patients who had experienced a negative life event in the 3 months prior to diagnosis indicated higher sexual care needs $(\beta=0.15)$ than patients who had not experienced such an event.

Anxiety and depressive symptoms were also significantly associated with care needs. Patients with higher levels of anxiety symptoms had higher unmet psychological care needs $(\beta=0.23)$ than patients with lower anxiety symptoms. Patients with higher levels of depressive symptoms had higher psychological $(\beta=0.38)$, physical/ daily living $(\beta=0.43)$, patient care/support $(\beta=0.17)$, and additional unmet care needs $(\beta=0.30)$, compared to patients with lower levels of this emotional state.

None of the patients' specific sociodemographic characteristics were significantly associated with the health system/ information domain.

\section{Discussion}

Nearly half of the Mexican breast cancer patients reported overall unmet supportive care needs following the cancer diagnosis. The highest unmet care needs were related to the health system/information domain, whereas the physical/ daily living needs were the lowest. Depressive symptoms were the most consistently associated factor to supportive care needs, as they were associated with four care needs domains.

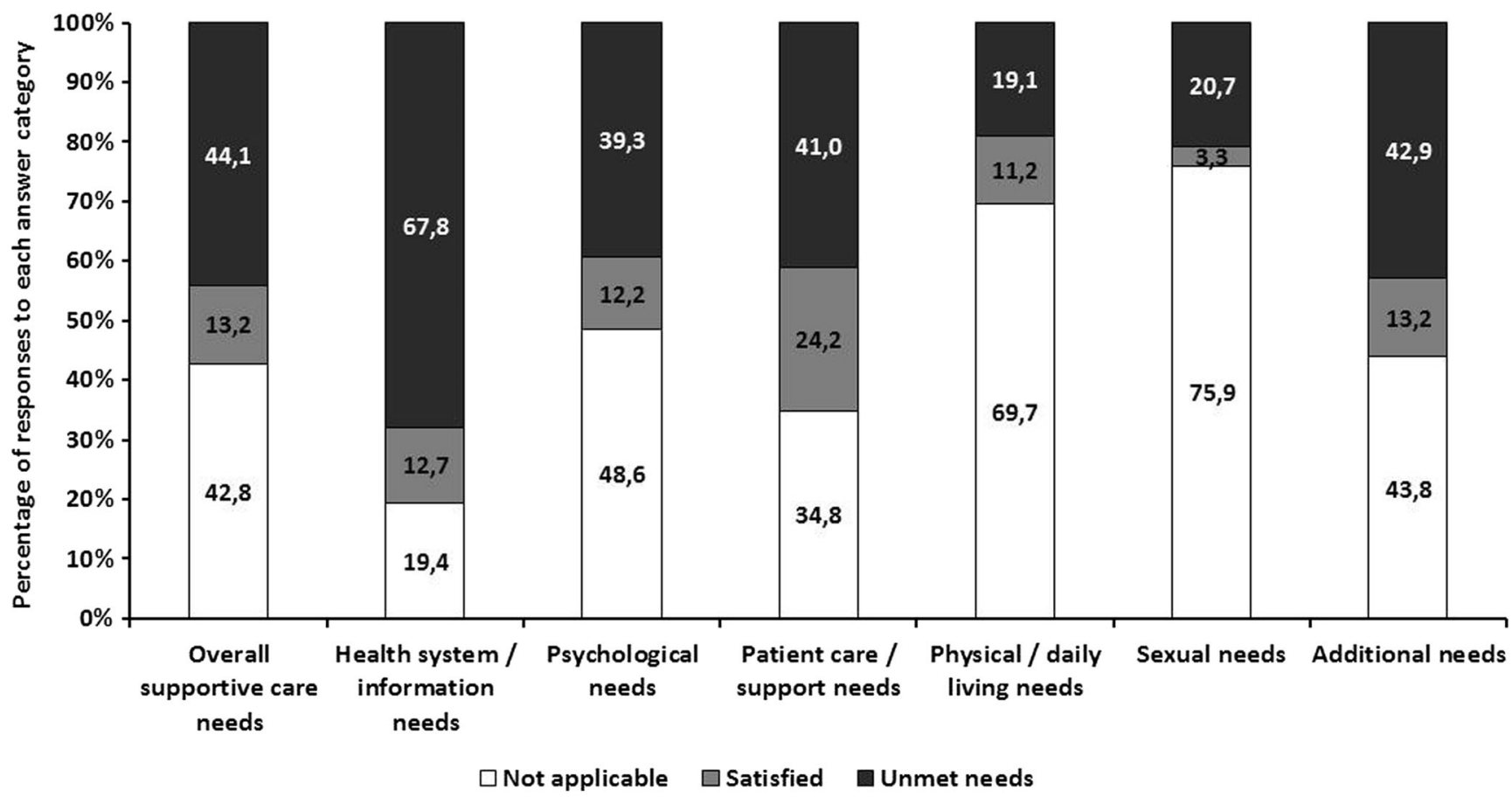

Fig. 1 Prevalence of supportive care needs based on the percentage of responses to answer categories 
Table 2 Ten most prevalent supportive care needs based on the response rate to the moderatehigh need answer categories $(n=173)$

\begin{tabular}{|c|c|c|c|}
\hline Ten most prevalent ${ }^{\mathrm{a}}$ & $n$ & $\%$ & $95 \% \mathrm{CI}$ \\
\hline 1. Being informed about things you can do to help yourself to get well & 123 & 71.1 & $64.1-77.5$ \\
\hline $\begin{array}{l}\text { 2. Having one member of hospital staff with whom you can talk to about all aspects } \\
\text { of your condition, treatment, and follow-up }\end{array}$ & 112 & 64.7 & $57.4-71.6$ \\
\hline $\begin{array}{l}\text { 3. Being informed about cancer which is under control or diminishing (that is, } \\
\text { remission) }\end{array}$ & 112 & 64.7 & $57.4-71.6$ \\
\hline 4. Being given explanations of those tests for which you would like explanations & 107 & 61.8 & $54.5-68.9$ \\
\hline $\begin{array}{l}\text { 5. Being given information (written, diagrams, and drawings) about aspects of } \\
\text { managing your illness and side effects at home }\end{array}$ & 106 & 61.3 & $53.9-68.3$ \\
\hline $\begin{array}{l}\text { 6. Being adequately informed about the benefits and side effects of treatments } \\
\text { before you choose to have them }\end{array}$ & 104 & 60.1 & $52.7-67.2$ \\
\hline $\begin{array}{l}\text { 7. Having access to professional counseling (e.g., psychologist, social worker, } \\
\text { counselor, and nurse specialist) if you, family, or friends need it }\end{array}$ & 102 & 59.0 & $51.5-66.1$ \\
\hline 8. Being informed about your test results as soon as feasible & 95 & 54.9 & $47.5-62.2$ \\
\hline 9. Being given written information about the important aspects of your care & 90 & 52.0 & $44.6-59.4$ \\
\hline 10. Being treated like a person, not just another case & 89 & 51.4 & $44.0-58.8$ \\
\hline
\end{tabular}

${ }^{a}$ All the items belong to the health system/information dimension
The prevalence rate of the overall unmet care needs in our sample was slightly lower, compared with previous research in breast cancer patients [21]. Importantly, patients in our study were recently diagnosed and had not yet started medical treatment. As suggested by earlier findings, perhaps more care needs arise as patients start medical treatment $[22,23]$. The finding that the greatest unmet care needs were clustered in the health system/information domain is consistent with previous studies among Mexican [10] and Asian cancer patients $[24,25]$. In contrast to other studies among Western breast cancer patients $[11,13,14]$, in our study, the psychological needs were relatively low. A possible explanation might be the differences in cultural context between Western, Asian, and Latin American countries. Mexican culture is predominantly characterized by collectivism and family attachment, which might buffer the psychological distress experienced by these patients.

Regarding the identification of subgroups of patients with higher needs of supportive care, our results are in line with previous studies showing an association between depressive symptoms and several supportive care needs domains [11]. In contrast to findings of earlier studies, in the present study, depressive symptoms were not associated with the health system/information or sexual domains $[13,14,22]$. Several studies have also shown the association between anxiety symptoms and supportive care needs of breast cancer patients [11]. In our study, anxiety was only associated with greater psychological unmet care needs, which is consistent with a previous study [26].

Sociodemographic characteristics also played a relevant role in predicting care needs. Consistent with previous studies on care needs in breast cancer patients, younger patients and patients with a partner showed more sexual unmet care needs than older patients or patients without partner [12, 13], and they also showed greater unmet physical/daily living needs [27]. Higher schooling was also related to more psychological unmet care needs $[12,13]$. In contrast, an earlier study reported higher psychological unmet care needs among breast cancer patients with lower education [14]. Clearly, more research is needed to elucidate the role of education in the unmet care needs of breast cancer patients.

Additionally, patients with comorbidities were in higher need of supportive physical/daily living care than patients without comorbidities. Also, patients who recently experienced a negative life event showed high sexual unmet care needs. This finding was unexpected and might be explained by the fact that patients who experienced a life event also showed significantly higher levels of anxiety and depression compared to those patients who did not experience one such event. Previous studies have not addressed the link between life events or comorbidities and supportive care needs in breast cancer patients, so further research is needed to clarify and confirm these relationships.

Some implications drawn from the results of the present study are the following: (1) regardless of the patients' characteristics, there is a rather widespread perceived lack of information regarding the disease and its treatments among Mexican breast cancer patients; (2) some changes should be made in the hospital system organization and institutional policies, since more than half of the participants preferred to have one member of the hospital staff to talk about all aspects of their condition (top two most prevalent care need); (3) depressed women with breast cancer are a specially vulnerable 
Table 3 Multivariate association of the sociodemographic, medical, and psychological characteristics of the patients on their supportive care needs

\begin{tabular}{|c|c|c|c|c|c|c|c|c|c|}
\hline \multirow[t]{3}{*}{ Characteristic } & \multicolumn{9}{|c|}{ Supportive care needs dimensions } \\
\hline & \multicolumn{3}{|c|}{ Psychological } & \multicolumn{3}{|c|}{ Health system/information } & \multicolumn{3}{|c|}{ Physical/daily living } \\
\hline & $\beta$ & $t$ & $P$ & $\beta$ & $t$ & $P$ & $\beta$ & $t$ & $P$ \\
\hline Age & -0.11 & -1.37 & 0.17 & -0.10 & -0.99 & 0.33 & -0.20 & -2.20 & 0.03 \\
\hline Number of children & 0.01 & 0.15 & 0.89 & 0.09 & 1.07 & 0.29 & 0.07 & 0.86 & 0.39 \\
\hline \multicolumn{10}{|l|}{ Marital status } \\
\hline With partner & 0.04 & 0.57 & 0.57 & -0.03 & -0.40 & 0.69 & -0.01 & -0.07 & 0.94 \\
\hline \multicolumn{10}{|l|}{ Without partner (reference) } \\
\hline \multicolumn{10}{|l|}{ Education } \\
\hline \multicolumn{10}{|l|}{ Low (reference) } \\
\hline Middle & 0.13 & 1.75 & 0.08 & 0.13 & 1.38 & 0.17 & -0.00 & -0.02 & 0.99 \\
\hline High & 0.17 & 2.06 & 0.04 & 0.16 & 1.62 & 0.11 & 0.05 & 0.18 & 0.59 \\
\hline \multicolumn{10}{|l|}{ Work status } \\
\hline Employed & 0.03 & 0.46 & 0.65 & -0.15 & -1.73 & 0.09 & 0.02 & 0.18 & 0.86 \\
\hline \multicolumn{10}{|l|}{ Housewife/retired (reference) } \\
\hline Time since diagnosis (months) & -0.07 & -1.02 & 0.31 & -0.12 & -1.57 & 0.12 & 0.04 & 0.52 & 0.60 \\
\hline \multicolumn{10}{|l|}{ Comorbidities } \\
\hline Yes & 0.11 & 1.53 & 0.13 & 0.16 & 1.85 & 0.07 & 0.15 & 1.95 & 0.05 \\
\hline \multicolumn{10}{|l|}{ No (reference) } \\
\hline \multicolumn{10}{|l|}{ Life event } \\
\hline Yes & 0.11 & 1.65 & 0.10 & 0.05 & 0.66 & 0.51 & 0.06 & 0.77 & 0.44 \\
\hline \multicolumn{10}{|l|}{ No (reference) } \\
\hline Anxiety & 0.23 & 3.20 & $<0.01$ & 0.09 & 1.02 & 0.31 & 0.04 & 0.46 & 0.65 \\
\hline Depression & 0.38 & 5.29 & $<0.001$ & 0.11 & 1.27 & 0.20 & 0.43 & 5.39 & $<0.001$ \\
\hline Adjusted $R^{2}$ & 0.372 & & & 0.052 & & & 0.227 & & \\
\hline F statistic & 10.22 & & & 1.85 & & & 5.56 & & \\
\hline$P$ & $<0.001$ & & & 0.05 & & & $<0.001$ & & \\
\hline \multirow[t]{3}{*}{ Characteristic } & \multicolumn{9}{|c|}{ Supportive care needs dimensions } \\
\hline & Patient & support & & Sexual & & & Additio & & \\
\hline & $\beta$ & $t$ & $P$ & $\beta$ & $t$ & $P$ & $\beta$ & $t$ & $P$ \\
\hline Age & -0.17 & -1.70 & 0.09 & 0.29 & -3.01 & $<0.01$ & -0.05 & -0.52 & 0.60 \\
\hline Number of children & 0.09 & 1.03 & 0.31 & 0.11 & 1.25 & .21 & 0.16 & 1.90 & 0.06 \\
\hline Marital status & & & & & & & & & \\
\hline With partner & -0.06 & -0.74 & 0.46 & 0.15 & 2.03 & 0.04 & -0.05 & -0.71 & 0.48 \\
\hline Without partner (reference) & & & & & & & & & \\
\hline Education & & & & & & & & & \\
\hline Low (reference) & & & & & & & & & \\
\hline Middle & 0.07 & 0.80 & 0.43 & 0.17 & 1.91 & 0.06 & 0.12 & 1.37 & 0.17 \\
\hline High & 0.11 & 1.10 & 0.28 & 0.15 & 1.62 & 0.11 & 0.14 & 1.47 & 0.14 \\
\hline Work status & & & & & & & & & \\
\hline Employed & -0.06 & -0.66 & 0.51 & -0.11 & -1.27 & 0.21 & 0.01 & 0.07 & 0.94 \\
\hline Housewife/retired (reference) & & & & & & & & & \\
\hline Time since diagnosis (months) & -0.10 & -1.30 & 0.20 & -0.09 & -1.23 & 0.22 & -0.12 & -1.60 & 0.11 \\
\hline Comorbidities & & & & & & & & & \\
\hline Yes & 0.15 & 1.73 & 0.09 & 0.11 & 1.36 & 0.18 & 0.00 & 0.02 & 0.98 \\
\hline No (reference) & & & & & & & & & \\
\hline Life event & & & & & & & & & \\
\hline Yes & 0.04 & 0.57 & 0.57 & 0.15 & 1.99 & 0.05 & 0.06 & 0.75 & 0.46 \\
\hline No (reference) & & & & & & & & & \\
\hline Anxiety & 0.15 & 1.77 & 0.08 & 0.02 & 0.30 & 0.77 & 0.12 & 1.44 & 0.15 \\
\hline Depression & 0.17 & 1.98 & 0.05 & 0.09 & 1.10 & 0.27 & 0.30 & 3.49 & $<0.01$ \\
\hline Adjusted $R^{2}$ & 0.088 & & & 0.140 & & & 0.143 & & \\
\hline F statistic & 2.51 & & & 3.54 & & & 3.60 & & \\
\hline$P$ & 0.01 & & & $<0.001$ & & & $<0.001$ & & \\
\hline
\end{tabular}

group, experiencing a range of unmet needs that warrant care, as unmet needs have been shown to be related to higher psychological distress and a decline in wellbeing [23]. Based on these implications, we consider that some steps should be taken to improve care. First, more research is needed to clarify and better understand this gap between the information as offered by health professionals and as perceived by patients. Thus, the next step would be to investigate which factors related to either patients or professionals, account for informational unmet care needs in breast cancer patients. Second, to improve the organization of health care services, we 
also suggest considering the possibility to permanently install a case manager [28]. Third, we suggest offering psychological care especially to patients with depressive symptoms, as they report the highest care needs.

When interpreting our results, several limitations need to be acknowledged. First, at the moment we started the study, there was no available validated Mexican version of the instrument to measure supportive care needs of patients, but now there is. We compared our version with the recently validated Mexican version, and although there were a few differences in wording, we found no significant differences in meaning of the items. Second, we included patients treated in a public hospital. As such, findings may not be generalizable to Mexican breast cancer patients treated in private hospitals.

Further studies should be conducted among Mexican and Latin American breast cancer patients to ascertain whether unmet supportive care needs patterns are similar to those found in the present study. Additionally, longitudinal studies must be conducted to check whether supportive care needs of the patients vary along the disease process.

In conclusion, the present study adds to the understanding of the supportive care needs among Mexican breast cancer patients treated in a public hospital. The results make evident that mainly health system/information needs arise at the time of diagnosis. Thus, implementing strategies to disseminate disease-related information among the patients is strongly suggested. Specifically, Mexican breast cancer patients suffering high levels of depressive symptoms are in the highest need of supportive care. These results provide information to the health care professionals and health policy makers in order to improve the organization of the services and to set up a clear framework for the provision of health care to Mexican breast cancer patients.

Acknowledgments This study was partly funded by grant 248477 from Mexico's National Council for Science and Technology (CoNaCyT).

\section{Compliance with ethical standards}

Conflict of interest There are no financial disclosures from any author. We have full control of all primary data, and we allow to the journal to review our data if requested.

Open Access This article is distributed under the terms of the Creative Commons Attribution-NonCommercial 4.0 International License (http:// creativecommons.org/licenses/by-nc/4.0/), which permits any noncommercial use, distribution, and reproduction in any medium, provided you give appropriate credit to the original author(s) and the source, provide a link to the Creative Commons license, and indicate if changes were made.

\section{References}

1. Justo N, Wilking N, Jonsson B, Luciani S, Cazap E (2013) A review of breast cancer care and outcomes in Latin America. Oncologist 18(3):248-256

2. Strasser-Weippl K, Chavarri-Guerra Y, Villarreal-Garza C, Bychkovsky BL, Debiasi M, Liedke PE et al (2015) Progress and remaining challenges for cancer control in Latin America and the Caribbean. Lancet Oncol 16(14):1405-1438

3. Ángeles-Llerenas A, Torres-Mejía G, Lazcano-Ponce E, UscangaSánchez S, Mainero-Ratchelous F, Hernández-Ávila JE et al (2016) Effect of care-delivery delay on the survival of Mexican women with breast cancer. Salud Pública México 58(2):237-250

4. Pérez-Fortis A, Schroevers MJ, Fleer J, Alanís-López P, VelozMartínez MG, Ornelas-Mejorada RE et al (2016) Psychological burden at the time of diagnosis among Mexican breast cancer patients. Psychooncology. doi:10.1002/pon.4098

5. Instituto Nacional de Estadística y Geografía. Principales causas de mortalidad por residencia habitual, grupos de edad y sexo del fallecido. http://www3.inegi.org.mx/sistemas/temas/default.aspx? $\mathrm{s}=\mathrm{est} \& \mathrm{c}=17484$. Accessed 25 February 2016

6. Lazcano-Ponce E, Mohar-Betancourt A, Meneses-García A, Hernández-Ávila M (2016) Cancer burden in Mexico: urgent challenges to be met. Salud Pública México 58(2):101-103

7. Wen K-Y, Gustafson DH (2004) Needs assessment for cancer patients and their families. Health Qual Life Out 2(1):1

8. Richardson A, Medina J, Brown V, Sitzia J (2007) Patients' needs assessment in cancer care: a review of assessment tools. Support Care Cancer 15(10):1125-1144

9. McElduff P, Boyes A, Zucca A, Girgis A (2004) The supportive care needs survey: a guide to administration, scoring and analysis. Centre for Health Research and Psycho-Oncology, Newcastle

10. Doubova SV, Aguirre-Hernandez R, Gutiérrez-de la Barrera M, Infante-Castañeda C, Pérez-Cuevas R (2015) Supportive care needs of Mexican adult cancer patients: validation of the Mexican version of the Short-Form Supportive Care Needs Questionnaire (SCNSSFM). Support Care Cancer 23(9):2711-2719

11. Fiszer C, Dolbeault S, Sultan S, Brédart A (2011) Prevalence, intensity, and predictors of the supportive care needs of women diagnosed with breast cancer: a systematic review. Psychooncology 23(4):361-374

12. Lam WWT, Au AHY, Wong JHF, Lehmann C, Koch U, Fielding R et al (2011) Unmet supportive care needs: a cross-cultural comparison between Hong Kong Chinese and German Caucasian women with breast cancer. Breast Cancer Res Tr 130(2):531-541

13. Schmid-Büchi S, Halfens RJG, Müller M, Dassen T, van den Borne B (2013) Factors associated with supportive care needs of patients under treatment for breast cancer. Eur J Oncol Nurs 17(1):22-29

14. Bredart A, Kop JL, Griesser AC, Fiszer C, Zaman K, Panes-Ruedin B et al (2013) Assessment of needs, health-related quality of life, and satisfaction with care in breast cancer patients to better target supportive care. Ann Oncol 24(8):2151-2158

15. Hwang SY, Park BW (2006) The perceived care needs of breast cancer patients in Korea. Yonsei Med J 47(4):524-533

16. Boyes A, Girgis A, Lecathelinais C (2009) Brief assessment of adult cancer patients' perceived needs: development and validation of the 34-item Supportive Care Needs Survey (SCNS-SF34). J Eval Clin Pract 15(4):602-606

17. Bonevski B, Sanson-Fisher R, Girgis A, Burton L, Cook P, Boyes A (2000) Evaluation of an instrument to assess the needs of patients with cancer. Cancer 88(1):217-225

18. Marteau TM, Bekker H (1992) The development of a six-item short-form of the state scale of the Spielberger State-Trait Anxiety Inventory (STAI). Br J Clin Psychol 31(3):301-306 
19. Spielberger CD, Gorsuch RLLER (1970) STAI Manual. Consulting Psychologist Press, Palo Alto, California

20. Kroenke K, Spitzer RL, Williams JBW (2001) The PHQ-9. Validity of a brief depression severity measure. J Gen Intern Med 16(9): 605-613

21. Boyes AW, Girgis A, D'Este C, Zucca AC (2012) Prevalence and correlates of cancer survivors' supportive care needs 6 months after diagnosis: a population-based cross-sectional study. BMC Cancer 12(1): 150

22. Au A, Lam WWT, Kwong A, Suen D, Tsang J, Yeo W et al (2011) Validation of the Chinese version of the Short-form Supportive Care Needs Survey Questionnaire (SCNS-SF34-C). Psychooncology 20(12):1292-1300

23. Harrison JD, Young JM, Price MA, Butow PN, Solomon MJ (2009) What are the unmet supportive care needs of people with cancer? A systematic review. Support Care Cancer 17(8):1117-1128

24. Liao MN, Chen SC, Chen SC, Lin YC, Hsu YH, Hung HC et al (2012) Changes and predictors of unmet supportive care needs in
Taiwanese women with newly diagnosed breast cancer. Oncol Nurs Forum 39(5):E380-E389

25. Park BW, Hwang SY (2012) Unmet needs of breast cancer patients relative to survival duration. Yonsei Med J 53(1):118-125

26. Au A, Lam W, Tsang J, Yau T, Soong I, Yeo W et al (2013) Supportive care needs in Hong Kong Chinese women confronting advanced breast cancer. Psychooncology 22(5):1144-1151

27. Griesser AC, Vlastos G, Morel L, Beaume C, Sappino AP, Haller G (2011) Socio-demographic predictors of high support needs in newly diagnosed breast cancer patients. Eur J Cancer Care 20(4):466474

28. Askew DA, Togni SJ, Schluter PJ, Rogers L, Egert S, Potter $\mathrm{N}$ et al (2016) Investigating the feasibility, acceptability and appropriateness of outreach case management in an urban Aboriginal and Torres Strait Islander primary health care service: a mixed methods exploratory study. BMC Health Serv Res 16(1):178 